\title{
Proposed Model and Approach to Graduate Mentorship and Supervision During COVID-19
}

\author{
Carol Nash ${ }^{1 *}$
}

\author{
1 History of Medicine Program, Department of Psychiatry, Faculty of Medicine, University of Toronto; \\ carol.nash@utoronto.ca \\ * Correspondence: carol.nash@utoronto.ca
}

\begin{abstract}
Before COVID-19, post-secondary learning was dominated by in-person, institution-organized meetings. With the March 12, 2020 lockdown, learning became virtual, largely dependent on commercial online platforms. Already more likely to experience anxiety and depression in relation to their research work, perhaps no students have endured more regarding the limitations imposed by COVID-19 on their mentorship and supervision than graduate students. The increase in mental health issues facing graduate students has come to the attention of their post-secondary institutions. Programs have been devised with the aim of reducing these challenges. However, the additional attention and funds to combat depression and anxiety have not shown anticipated results. A new approach to mitigate anxiety and depression in graduate students through mentorship and supervision is warranted. Offered here is an award-winning model featuring self-directed learning in a community based on consensus decision-making where consensus represents the adding together of different points of view rather than agreement. The approach is non-hierarchical in structure, based in narrative research. The proposed model and approach are presented and limitations considered. This model and approach are offered as a likely solution to ebb the increase in anxiety and depression in graduate students - particularly in response to COVID-19.
\end{abstract}

Keywords: COVID-19; graduate students; anxiety; depression; mentorship; supervision; narrative research

\section{Introduction}

Mental health issues are on the rise for all post-secondary students. [1,2] In post-secondary institutions supporting graduate programs, the most persistent and evident challenges facing graduate students today are those arising from anxiety and depression caused by stress related to unmet research expectations. [3,4] Graduate students have been found six times as likely to experience depression and anxiety as compared to the general population. [5] This problem has only been further exacerbated by the isolation and strain graduate students now feel as a result of the limitations imposed on their research work as a result of COVID-19. [6]

An inability of graduate students to flexibly persist, through the period between the initial idea related to their research and the fulfilling of final program requirements, acts as an indicator of potential anxiety and depression. [7,8] Overwhelming feelings resulting from existential crises [9]-while knowing their degree requires timely completion of their research - mean that, when things are not going as planned with their work, graduate students may initially exhibit anxiety concerning their future that, if the necessary clarity is not regained, develops into deep and all-consuming depression in relation to their lived experience. When anxiety continues to accompany depression, tragically, 
the likely result is suicide. [10] If students recover, this existential challenge has at best lengthened the time to completion of the degree; if students survive but do not recover, these students and their supporting academic institutions suffer the loss of what might have been very productive and internationally recognized research. The challenge is thus beyond a personal problem; it is critical to the future of graduate studies.

With respect to the competitive research world, graduate students suffer these difficulties because, as a group, they represent the very lowest rung of the research ladder. [11] They are isolated in their work, require mentorship in various aspects of academe, [12] and the supervisory communication they experience may be difficult and anxiety provoking. [13] When, because of COVID-19 restrictions, they are unable to meet directly with their mentors to increase employment opportunities and develop professional skills, or with their supervisors to gain insights into their work, their anxiety and/or depression can be further increased.

Academic institutions have undertaken to improve the outcome of these difficulties faced by many graduate students through increasing access to university mental health services. [14] With a graduate student population of over 20,000 students, [15] this perception of the need to improve funding to graduate mental health services has been taken up by the author's own academic institution, the University of Toronto. [16,17] In June 2020, the University's School of Graduate Studies issued the School of Graduate Studies Mental Health Working Group Recommendations to create a concerted plan to improve the mental health of its graduate students. [18] However, in each of these encouraging strategies, the problem of graduate student mental health has been assumed a personal one related to helping individual students so that they can reenter the hierarchical and uncertain life of graduate students. Even though much effort has been put into reducing the stigma of mental health problems, [19] still, seen as merely a personal problem, the student remains the focus of the difficulty and it is the student who is expected to change to get back to their graduate work.

More resources are being put into mental health of graduate students. [20] This is especially so as a result of COVID-19. [21] Yet, if this way of dealing with anxiety and depression were optimal we would be seeing at least a levelling off of the number of students looking for help with anxiety and depression. Instead, these mental health issues are on the rise at an alarming rate [22] and have taken off exponentially as a result of COVID-19. [23]

To see a reduction in anxiety and depression in graduate students, a new perspective is required regarding to whom these issues belong. The cause of mental health problems in graduate students, rather than being treated as an individual failing, needs to be recognized as a systemic issue resulting from the particular type of competition that is academe.

Graduate education has a long history of supporting hierarchical, disciplinary research. This type of research produces excellence within the discipline but does so at the cost of the mental health of researchers who are not at the top, most specifically, graduate students. [24] As more and more undergraduate students choose graduate education, the number of graduate students aiming to get to the top increases. [25] Unfortunately, the pinnacle still holds few places, so most graduate students never make it to the top. In the meantime, unable recognize truth related to their discipline at the level at which they research, if they leave their graduate studies, they feel as if they have achieved nothing of value, increasing their anxiety and depression. Left to flounder, it is the culture of institutional neglect experienced by those students who are not at the top that causes them to consider leaving their graduate work. [26] 
If graduate schools are truly serious about wanting to improve the graduate student experience, they need to question and change the status quo regarding the research life of a graduate student in a way that will maintain excellence in research pursuits but at the same time improve both mentorship and supervision to lessen the anxiety and depression experienced by an increasing number of graduate students. The aim needs to focus on reducing the isolation of graduate students - creating a community of researchers who work together, rather than merely in competition with each other. As such, the type of model and approach to graduate studies that perhaps could be created to have the best chance of success is the one to be proposed here.

\section{Results}

What graduate schools have not investigated at an institutional level is non-hierarchical mentorship and supervision of graduate students. In this model, beyond organizing research by discipline, researchers become part of interdisciplinary and multi-academic level groups where each person's contribution as a point of view is considered equal and necessary to the group.

How these groups would be structured would be similar to the Health Narrative Research Group that has been facilitated through the University of Toronto Faculty of Medicine since 2015, for which the facilitator, the author of this paper, has received two awards from that institution for program excellence in results $[27,28]$.

The Health Narratives Research Group (HeNReG) allows researchers the opportunity to take the personally relevant stories that initiated their commitment to health care and develop them into narratives with a particular point of view. The process includes both personal reflection and the willingness to share one's story and gain additional insights from the rest of the group. The aim is to help researchers reduce the depression and/or anxiety that often accompany work as a researcher. Information on the efficacy of this group from a number of perspectives-especially with respect to COVID-19- has been published in various journals. [29,30,31,32]

The HeNReG is a weekly, voluntary, non-credit group, free of charge, open to any member of the university community interested in health care. Diversity of membership is both supported and encouraged. The group includes students (undergraduate and graduate), Faculty, administrators and alumni. Participants range from various disciplines. For the 2020/21 academic year they include: Diaspora and Transnational Studies, Paediatrics, Education, Statistical Science, Economics, Bioinformatics and Computer Science, Narrative Research, Social Work, Information Science, English, Neuroscience, Psychology, Bioethics, Family Medicine, Health Studies, Immunology, Medicine, Drama, and East Asian Studies.

The HeNReG elicits the points of view of the researchers regarding how they see themselves as healthcare researchers through five minute writing prompts that follow a process. The purpose of the prompts is to take the researcher's story and develop it into a narrative with a particular point of view. It is a method that acts as an example of Wittgenstein's philosophy of therapy undertaking [33] and emphasizes Russell's view that education with the freedom to develop a contemplative habit of mind is necessary to develop an appreciation for what is intrinsic to the significance of knowledge. [34]

The prompts, developed by the facilitator, are arranged in a particular order. The first prompt of the year is "Describe yourself regarding your research related to health." This prompt elicits the story representing the researcher that would be the basis of their answers to the prompts that follow. 
Questions are then asked each week of participants to construct each researcher's point of view on their research story. These questions are arranged from those that are most objective to those that are increasingly subjective. As such, this is the order of questions: "when," "where," "who," "what," "how," and then "why." For the HeNReG process, the first four questions ("when," "where," "who," "what"). have four weeks of prompts; the next two questions ("how," and then "why"), six weeks of prompts each. Members are asked to respond to the questions stream of consciousness and should aim to write for no longer than five minutes.

A private Facebook group is set up yearly by the facilitator for the purpose of communication. For the 2020/21 academic year, as a result of COVID-19, there have been no in-person meetings of the HeNReG. All meetings have taken place synchronously on the hybrid private Facebook group. In order to participate in the weekly meetings, all members of the HeNReG must become Facebook friends of the facilitator to be invited to the private Facebook group. Members may or may not decide to become Facebook friends with any of the other participants.

The facilitator initially posts the descriptions that have been provided by participants in answer to the first prompt for each member at the initial online meeting. At subsequent meetings, the facilitator poses the question of the week through individual messages via Messenger and participants ask additional questions of each other in the private Facebook group, making sure their question begins with the same word of the week. The facilitator, during the synchronous, weekly, two-hour meeting, posts responses to the prompts and poses questions to each member. Members are encouraged to ask further questions to each other on the private Facebook group either during the synchronous meeting or at another, convenient time for them as well as to read the posts they are receiving regarding their research on the private Facebook group and respond to questions posted by other members either synchronously at the time of the meeting or asynchronously at another time.

Another aspect of the HeNReG that has been shown to help reduce anxiety and depression is the promotion of doodling during the academic meeting. [35] Everyone participating in the online meeting is encouraged to doodle over the two hour period. Doodling can be done throughout the meeting at any time members are not otherwise engaged with posing questions to others or answering questions others have provided regarding their response to the writing prompt. At the end of the meeting, members are asked to send their doodles to the facilitator who then posts their doodles and their descriptions of the doodle on the private Facebook group.

Feedback for the HeNReG is formally requested by the facilitator twice per year, at the last meeting in December and the last meeting in April. The feedback form is one common to the Health, Arts and Humanities Program of the Department of Psychiatry, University of Toronto and is given as a Google survey to be completed online. The results of these surveys are compiled and then conveyed to the Chair of the History of Medicine Program (the academic home of the facilitator) and the Director of Health, Arts and Humanities in the Department of Psychiatry.

The HeNReG is a group focused on health research serving approximately 20 researchers per year in various stages of their research programs. However, narrative research groups need not focus on health. They could apply to the complete experience related to graduate studies. In this case, the initial request of the researchers could be, Describe yourself regarding your research. As well, many groups of twenty could be set up to serve additional researchers. 
The point is that in these groups, mentorship and supervision have a different meaning than they do in hierarchical research. In these proposed research groups, mentorship is a joint undertaking of all members of each other. Supervision results from those members who are most able to communicate their positions. In other words, the more easily and completely your point of view regarding your research is understood by others in the group, the greater your role as a supervisor. As such, "mentor" describes members willing and able to provide questions to other members to encourage them to look more deeply at what they value in their research, helping them to develop routes to what is known by other researchers. In these roles, rather than telling graduate researchers what to do from their particular hierarchical position, each member is able to reach out to others to form an equal, academic connection.

\section{Discussion}

To understand the HeNReG model with respect to mentorship and supervision of graduate students, the background of the approach-both philosophically and with respect to its particular features-will be presented.

\subsection{Two ways to approach truth through research}

Truth researchers are investigating can be conceptualized as a landscape with obstacles. To contend with those obstacles, there are two approaches to truth [36] that can be presented best through an analogy.

The first approach to truth is to climb to the top of the highest barrier and survey the landscape of truth from the highest point. This, in effect, represents the competitive research undertaking that graduate students generally find in their disciplines. Obstacles in the landscape of truth are barriers to eliminate through climbing higher; and higher views supersede lower ones because research is recognized as hierarchical. The purpose in this view of truth is to create the most accurate aerial view of the landscape dependent on the view at the top. It is a view, attainable by very few, that only those holding the esteemed position of being at the top of the discipline can achieve. [37]

The second approach to truth is that which is defined by narrative research [38] where each researcher is considered equal in having a unique, identifiable and communicable position that can be shown in the landscape. [39,40] This uniqueness represents their point of view regarding the obstacles and, rather than climbing to the top to get an overall view of the landscape, obstacles in the landscape are interpreted as landmarks to use as signposts in constructing various routes around the landscape. [41] Each point of view is equal in being necessary in successfully navigating the landscape of truth as the routes created from one point of view to another can be added together in a way that is non-hierarchical-as such, creating a "street view" of the landscape.

Hierarchical, disciplinary research is open to a few and the only truly relevant work is done by those at the top of the obstacles in the landscape because, in this analogy, it is only they who can see the surroundings unobstructed. Once a researcher is at the top in disciplinary research, the researcher is excellent at identifying relationships both quickly and expansively. We continue to need this type of research producing clear and comprehensive views. The problem is, before the researchers in this hierarchy are at the top they are unable to get an unobstructed view and what it is they see may be at the time unrecognizable and then understood as distorted once they are able to climb higher over the obstacles. Graduate students following this hierarchical model for their research may be told analogously by their supervisors that there is an unimpeded view at the top; however, until they are able to reach the summit, it is no wonder that their lack of clarity regarding the truth of their discipline leaves graduate students stressed to the point of becoming anxious and depressed. 
In contrast, the aim in non-hierarchical narrative research is to connect researchers and understand different points of view given the obstacles with which each researcher contends. In fact, in narrative research, all points of view are necessary in order to get a complete picture of the landscape of truth - a view inspired by the later work of Wittgenstein. [42] Based on this view, supervisors are those who have more experience explaining their position in the landscape to graduate students while mentors are those who, by identifying how to get from their point of view to that of the graduate student, help the graduate student in developing routes to other points of view. It is in having a position qua position, the point of view of both the supervisor and mentor is equal to the graduate student. Accepted as an equal, working along-side their supervisor and in association with mentors, graduate students as narrative researchers can avoid the anxiety and depression of the graduate student when working hierarchically.

\subsection{Self-direction in graduate work}

Perhaps the most important difference between graduate studies and other forms of learning is the necessity of graduate students to be able to self-direct their learning. Nevertheless, students' transition toward internally driven ways of meaning making are not without difficulties. [43] If unreflective about their approach to their studies, graduate students may turn to supervisors and look for mentors to tell them exactly what to do or who impose a structure that guides them through a pre-determined process. [44]

Graduate students who look for this type of other-directed support by supervisors and mentors are those who have traditionally been referred to as requiring "hand-holding" by graduate faculty. [45] Yet, students have good reason to worry about not doing what is required given the hierarchical relationship between graduate students and their supervisors and mentors when, among other things, a very important consideration for them is the increasing burden of their student debt. [46] There are many considerations regarding how graduate students select those who can advise them given the various limitations imposed by this hierarchical structure. [47]

The importance of learning self-direction by graduate students is a necessity. Therefore, any ways that can be found to reduce the ominous weight of the hierarchy and make the graduate student feel comfortable and supported in self-directing would be of value. Introducing narrative research to graduate studies is one proven way and serving the purpose and interests of inviting self-direction and can also have a positive influence on the groups and organizations in which they work. [48]

\section{Materials and Methods}

\subsection{Phase I}

Adopting this model of mentorship and supervision-as self-directing, non-hierarchical and supportive of developing personal narratives - can be expected to reduce the anxiety and depression increasingly faced by graduate students as it has in the Faculty of Medicine with the HeNReG. The role of graduate mentorship and supervision would be to introduce this model beginning with those directly associated with each aspect of graduate education. This model must be understood and championed by those invested graduate studies for them to be ambassadors of the model.

Nevertheless, in keeping with the intent of non-hierarchical methods, the way to approach the various stakeholders of graduate education is by initially finding out and recording their current views on graduate supervision and mentorship before any new model is introduced. 
In the non-hierarchical approach, the stakeholders include everyone involved with graduate education: graduate students through their elected student body, graduate faculty through their elected academic representatives, graduate studies administrators, the support staff for graduate education and graduate alumni.

The first few months of implementing the proposal would entail the facilitator meeting with as many representatives from each of these groups as possible. In keeping with the restrictions of COVID-19, these meetings would take place with a video conferencing tool. It should be cautioned, though, that the video conferencing platform currently most popular, Zoom, is a commercial platform and has not been developed specifically for academic meetings. As a result, it has its limitations. With certain of these groups, who it is that would be included in these video conferencing meetings would be evident - there are a limited number of graduate studies administrators, for example, and who they are and how to get in touch with them is easily determined. For other groups, such as graduate alumni, contact information may be out of date and include duplicate records. As such, getting in touch with all those recognized as involved with graduate education may take time and effort.

When the facilitator contacts these various groups, members would be asked what they think of the current methods of graduate supervision and mentorship. Recording and analyzing their responses using qualitative research methods appropriate for narrative research [49] would take place well before they are introduced to the notion that a major change is planned to take place in how both are undertaken.

After this preliminary information is gathered, the facilitator -in administering this process-would compile it and write a report on the current perceptions of graduate supervision and mentorship associated with graduate studies in the academic institution. This report would be submitted to the graduate studies administrative team and presented to the elected members of the faculty, students and alumni. A forum would also be set up to present the results to graduate support staff.

In presenting this report, the facilitator would look for feedback from the stakeholders. The questions asked and the concerns provided would be those incorporated into the next phase of modifying graduate supervision and mentorship at the academic institution to increase self-direction and decrease anxiety and depression in graduate students through non-hierarchical narrative research.

\subsection{Phase II}

Those directly involved graduate education would be invited by the facilitator to become part of one of a number of Graduate Narrative Research Groups based on the work of the Health Narratives Research Group since 2015 in the Faculty of Medicine, University of Toronto. Potential members directly associated with graduate studies-students, faculty, administrators, support staff and alumni-would receive an email from the facilitator asking if they would like to be involved in a pioneering project to improve their own understanding of their relationship to graduate education and, at the same time, help other members of graduate studies understand theirs. If they agree, they would be sent information on how the group would operate, including being part of one of the of a number of private Facebook groups set up for only these members.

The groups would be created with the intent of having a diverse composition to each group including representatives from each of the stakeholder groups of various academic disciplines. Once the groups are formed, the facilitator would send weekly prompts to the group members over Messenger for them to respond to in writing for five-minutes. How many are formed will depend on the number of representatives of the various stakeholders in graduate education at a particular institution. Their response would be 
posted to the private Facebook group during a two-hour synchronous time period in which members of the group can ask questions of the others to clarify the relationship each member has to the School and answer questions they themselves receive from other members.

The initial prompt would be, "Describe yourself regarding graduate studies." From that question, each week a new prompt would be provided starting with questions that are most objective moving to those that are increasingly subjective. As such, the prompts would be questions that begin with "when," move to "where" questions, then "who," "what," "how," and "why." The different private Facebook groups, which would have their synchronous meetings at separate times organized by the facilitator, would run for 24 weeks from the first week of October to the last week in March. There would be four weeks of each type of question (differing from the HeNReG, which runs for 28 weeks) to have group ending date coincide with the academic yearend.

Concurrent with the question asking of the synchronous meeting, group members would be encouraged to doodle as they wait for others to ask and answer questions. The purpose of the doodling is to help to reduce any anxiety and depression in group members who are experiencing these difficulties. The ability of doodling to act as measure of the mental state of some researchers has been demonstrated in HeNReG groups and has been reported. [35]

Being part of the proposed Graduate Narrative Research Group, those associated with the graduate learning would see what it is like to experience non-hierarchical supervision and mentorship in that, for the purposes of the group, each person would be treated as equal in helping the others understand their relationship to graduate studies. This includes the facilitator of each of the separate Graduate Narratives Research Groups who would act as an equal member.

This method must be experienced to be understood. It is for this reason that a change can begin to take place in the School related to supervision and mentorship only once all the stakeholders can themselves be part of such a research group where each person's voice counts and is equal. This is a completely different type of supervisory and mentoring relationship than that with which most of those associated with academe have experienced.

These initial, narrative research groups would take place over one academic year. During this time, a feedback form would be provided twice yeary to all members of the each of the private Facebook groups, at the end of the fall term and again at the end of the spring term. The results from this feedback form would then be tabulated and presented by the facilitator in a yearly report to the council with charge of graduate education at the institution.

\subsection{Phase III}

From the report presenting results of these meetings of the Graduate Narratives Research Groups, guidance would be sought from the graduate council concerning the construction of a policy that would be written regarding changes to supervision and mentorship in graduate studies with the purpose of including non-hierarchical methods in graduate studies to increase self-directed learning in graduate students and consensus decision making based on narrative research. This policy would be written in conjunction with representatives from each of the stakeholders of graduate education who participated in the Graduate Narratives Research Groups.

The expectation is that, based on their experiences participating with a Graduate Narratives Research Group and with the help of the new policy with respect to supervi- 
sion and mentorship, this type of non-hierarchical group supporting self-directed learning and consensus decision making through narrative research would be able to be initiated by any person associated with graduate studies to help with self-reflection on their relationship to graduate studies. In doing so, the stress that leads to anxiety and depression would be reduced and, as such, the School would become a more socially engaged and well-integrated organization.

\section{Limitations}

\subsection{Facilitator}

A limitation of this proposal is the necessity of finding the right type of facilitator for the proposed Graduate Narrative Research Groups. The qualifications to be a facilitator are many and various. As well, the facilitator must be comfortable with and thrive in a non-hierarchical environment. Within the hierarchical domain of graduate studies, such a person is a rarity.

Important to the success of these Graduate Narratives Research Groups is the ability of the facilitator to gain the trust of all those participating in each individual group. Given that the group is grounded in non-hierarchical relations, the most important requirement for a facilitator of the group is an understanding of, and familiarity with, participating in non-hierarchical groups where the facilitator has been an equal member. Such a person would have been drawn to such organizations in the past in both student government and broader university relations. As well, the person best suited to act as facilitator would be an active alumni member, volunteering their time to mentoring, at their alma mater.

The facilitator should also be creative in originating writing prompts and distributing them to group members by Messenger, methodical in posting information to the private Facebook group and persistent to keeping participants involved-sending messages to engage them in the online discussion when they are on Facebook but have not yet signed on to the group to participate. Furthermore, the facilitator must have the ability to think constructively about the feedback received by the group members twice a year to find ways to improve the functioning of the group based on the responses that participants provide.

With respect to the outcome of the Graduate Narratives Research Groups, the facilitator should be capable of devising policy for the mentorship and supervision of graduate students in collaboration with all stakeholders. At the same time, the facilitator should be able to analyze and evaluate the groups' results as a form of qualitative research relevant to narrative research to be published in appropriate and significant peer-reviewed journals.

Finding such a facilitator will not be simple. However, once identified, the facilitator will have the ability devise and initiate and maintain each of the three phases suggested for creating these non-hierarchical narrative research groups to encourage self-direction and consensus decision making in graduate students.

\subsection{Risking Self-Direction}

The need to improve supervision and mentorship in graduate studies results from increases in each of: the number of graduate students, the high cost of graduate education, the amount of information that must be absorbed and understood by graduate students, and the expectation that graduate students are to publish regularly in peer-reviewed journals. Graduate education has become a progressively high stakes, risky business. As a result, graduate students have become more reluctant to self-direct 
their learning. This is especially so as they view their own contribution to scholarship as limited and at the lowest rung of the academic ladder.

Yet, in order for graduate students to be successful, they must take the risk of being self-directed in their work. How to do this has been the problem. Especially when graduate students may be suffering from anxiety and depression as a result of the enormous stress under which they feel.

\subsection{Situation of Graduate Students}

A method that has been successfully introduced in the Faculty of Medicine through the Health Narratives Research Group has been offered as a viable and peer-reviewed option. However, there are limitations to this method that may result based on the current situation in which graduate students find themselves.

Although these problems have not been recognized with the HeNReG in particular, other non-hierarchical groups have identified that those who participate in the groups-entirely conditioned to hierarchy and accepting of its necessity-may see the narrative groups as a waste of time and merely an opportunity to focus on themselves without regard for what they might learn from others. [50]

To mitigate these concerns, the facilitator of this model would take note of group participants who appear to be getting less from the opportunity to self-direct their learning than others and communicate with them about these concerns over Messenger. Messenger is chosen over Zoom because the conversations can be recorded and used in documents by the graduate student. Yet, it is less formal and less intimidating than the use of email, which may be interpreted as a method of communication associated with hierarchical structures not in keeping with the interests of current graduate students. [51]

\subsection{COVID-19}

A final limitation is the COVID-19 pandemic itself. As of the third week in January 2021, both Pfizer and Moderna have produced vaccines that are being administered worldwide. Each require two doses, the timing of which is less than thirty days apart. [52] Yet, there is a scarcity of material and labor to create the billions of doses required. [53] Until enough people have received the vaccine, lockdown measures are considered the most effective strategy to stopping the spread of COVID-19. [54] These lockdowns place an additional strain on graduate students with respect to worry concerning their own health and that of their families as well as a decreased ability to be productive as a result of working at home while contending with family matters. [55] Although graduate students may want to participate in these non-hierarchical Graduate Narrative Research Groups, the toll of the pandemic on their personal and professional lives may be too great for them to find the time or energy to participate.

It is unknown how long COVID-19 will be so prevalent that lockdowns must continue. However, not all graduate students are equally affected by the constraints of lockdown. The overriding feature for determining the ability of people to cope with lockdown appears to be resiliency. Furthermore, psychological resilience in the face of the pandemic is related to modifiable factors including physical exercise and personal support by family, friends and a clear belief system. [56] Yet, given that the aim of this proposal is to help reduce anxiety and depression in graduate students, these students are those less likely to demonstrate resilience. Therefore, it can be antiquated that they will be more affected by the lockdowns than other graduate students and less able to engage in modifiable factors. Fortunately, cognitive emotion regulation strategies can contribute to resilience in patients with depression and/or anxiety disorders. [57] The proposed Graduate Narratives Research Groups is one such strategy. 


\section{Conclusions}

The importance of effective supervision and mentorship through non-hierarchical methods has become increasingly clear and prominent. [58,59] As well, the need for institutional reform in graduate education has become evident. [60] If this proposed model for introducing self-directed learning through narrative research is initiated in graduate studies this would be in line with supporting diversity, equity, fairness and ethical conduct in graduate education. As well, it would do much to encourage a close and positive relationship between graduate students and their supervisors and mentors. Furthermore, it would improve the student experience and support mental health, especially during the COVID-19 pandemic.

Graduate mentorship and supervision are seen to represent an area primed for new models and approaches. The method and approach to graduate mentorship and supervision that has here been proposed is one that has proven successful in the University of Toronto Faculty of Medicine since 2015. It would be a coordinated effort across multiple units, one that is highly visible and, through the research that would be undertaken and submitted for publication in peer reviewed journals by the facilitator of the model, a program that is a leader to help bring about the change. During the COVID-19 pandemic, the need for a new model for graduate mentorship and supervision is imperative. The one outlined in this proposal has the ability to not only to improve graduate mentorship and supervision during COVID-19 times, it also offers a lasting solution to reducing anxiety and depression suffered by an increasing number of graduate students.

Funding: This research received no external funding.

Acknowledgments: I wish to thank Edward Shorter, Jason A. Hannah Professor in the History of Medicine, University of Toronto for his continuing support of my work and Allan Peterkin, Professor of Psychiatry and Family Medicine at the University of Toronto and director of the Health, Arts and Humanities Program for his support of the Health Narratives Research Group since 2015 through the Mount Sinai Hospital.

Conflicts of Interest: The author declares no conflict of interest.

\section{References}

1. Linden, B.; Stuart, H. Post-Secondary Stress and Mental Well-Being: A Scoping Review of the Academic Literature. Canadian Journal of Community Mental Health 2020, 39 (1), 1-32. https://doi.org/10.7870/cjcmh-2020-002.

2. Gotlib, D.; Saragoza, P.; Segal, S.; Goodman, L.; Schwartz, V. Evaluation and Management of Mental Health Disability in Post-Secondary Students. Current Psychiatry Reports 2019, 21 (6), 43. https://doi.org/10.1007/s11920-019-1024-1.

3. Kaler, Lisa S.; Stebleton, Michael J. Graduate Student Mental Health: Examining an Overlooked Concern. Journal of Student Affairs 2019-2020, XXIX, 101-110.

https://mountainscholar.org/bitstream/handle/10217/211436/JOUF_JOSA v29 2019-2020.pdf?sequence=1\#page=102 Accessed on January 15, 2021.

4. Pain, Elizabeth. Graduate Students Need More Mental Health Support, Study Highlights. Science March 6, 2018. https://doi.org/10.1126/science.caredit.aat5139.

5. Evans, T.M.; Bira, L.; Gastelum, J.B.; Weiss, L.T.; Vanderford, N.L. Evidence for a Mental Health Crisis in Graduate Education. Nature Biotechnology 2018, 36 (3), 282-284. https://doi.org/10.1038/nbt.4089.

6. Suart, C., Suart, T.N., Graham, K., Truant, R. When the Labs Closed: Graduate Students' and Postdoctoral Fellows' Experiences of Disrupted Research During the COVID-19 Pandemic. Research Square. January 24, 2021, 1-34. https://doi.org/10.21203/rs.3.rs-59050/v1. 
7. Gilbert, K.E., Tonge, N.A., Thompson, R.J. Associations between depression, anxious arousal and manifestations of psychological inflexibility. Journal of Behavior Therapy and Experimental Psychiatry. March 2019, 62, 88-96. https://doi.org/10.1016/j.jbtep.2018.09.006.

8. Yu, Y., Yu, Y., Lin, Y. Anxiety and depression aggravate impulsiveness: the mediating and moderating role of cognitive flexibility, Psychology, Health \& Medicine 2020, 25(1), 25-36. https://doi.org/10.1080/13548506.2019.1601748.

9. Besharat, M. A., Khadem, H., Zarei, V., \& Momtaz, A. Mediating Role of Perceived Stress in the Relationship between Facing Existential Issues and Symptoms of Depression and Anxiety. Iranian Journal of Psychiatry 2020, 15(1), 80-87.

10. Goldberg, D., \& Fawcett, J. The Importance of Anxiety in Both Major Depression and Bipolar Disorder. Depression and Anxiety 2021, 29(6), 471-478. https://doi.org/10.1002/da.21939

11. Maestre, F.T. Ten simple rules towards healthier research labs. PLoS Computational Biology 2019, 15(4): e1006914. https://doi.org/10.1371/journal.pcbi.1006914

12. Lechuga, V.M. Faculty-graduate student mentoring relationships: mentors' perceived roles and responsibilities. Higher Education 2011, 62, 757-771. https://doi.org/10.1007/s10734-011-9416-0.

13. Coaston, S.C. Cultivating self-compassion within the supervision relationship. The Clinical Supervisor 2019, 38(1), 79-96, https://doi.org/10.1080/07325223.2018.1525596.

14. Hazelrigg, K., Woodworth, M. New Initiative to Support Graduate Student Mental Health and Wellness. Council of Graduate Schools August 20, $2019 . \quad$ Available online: https://cgsnet.org/new-initiative-support-graduate-student-mental-health-and-wellness (accessed on 22 January 2021).

15. Quick Facts (2020) Student Enrolment. University of Toronto Fall 2019-2020. Available online: https://www.utoronto.ca/about-u-of-t/quick-facts (archieved 22 January 2021).

16. Provostial Advisory Committee on Student Mental Health. Report of the Provostial Advisory Committee on Student Mental Health: The University of Toronto Student Mental Health Strategy and Framework. University of Toronto October 2014. pp. 1-61. Available online: https://www.provost.utoronto.ca/wp-content/uploads/sites/155/2018/03/Report-on-Student-Mental-Health.pdf (accessed on 15 January 2021).

17. news.utm@utoronto.ca. U of T announces action plan on student mental health. U of T News April 1, 2019. Available onine: (https://www.utm.utoronto.ca/main-news/u-t-announces-action-plan-student-mental-health (accessed on 15 January 2021).

18. School of Graduate Studies Mental Health Working Group. Recommendations; School of Graduate Studies, University of Toronto, June 2020. pp. $\quad$ 1-5. Available online: https://www.sgs.utoronto.ca/wp-content/uploads/sites/253/2020/10/Mental-Health-Working-Group-Recommendations-FINA L.pdf (accessed on 22 January 2021).

19. Levine, R. U of T expert on the rise of students seeking help for mental health. U of T News April 3, 2019. Available online: (https://www.utoronto.ca/news/u-t-expert-rise-students-seeking-help-mental-health (accessed on 15 January 2021).

20. Levecque, K., Anseel, F., De Beuckelaerd, A., Van der Heyden, J., Gislef, L. Work organization and mental health problems in PhD students. Research Policy 2017, 46, 868-879. https://dx.doi.org/10.1016/j.respol.2017.02.008.

21. Lane, R. Graduate students: Mind your mental health this fall amid pandemic stress. Chicago Sun*Times August 28, 2020. Available

online:

https://chicago.suntimes.com/well/2020/8/28/21404295/graduate-students-mental-health-covid-19-pandemic-college-resources (accessed on 22 January 2021).

22. Eleftheriades, R., Fiala, C., \& Pasic, M. D. The challenges and mental health issues of academic trainees. F1000Research 2020, 9, 104. https://doi.org/10.12688/f1000research.21066.1 
23. Chirikov, I., Soria, K. M., Horgos, B., \& Jones-White, D. Undergraduate and graduate students' mental health during the COVID-19 pandemic 2020. SERU Consortium, University of California - Berkeley and University of Minnesota. Available online: https://escholarship.org/uc/item/80k5d5hw (accessed on 22 January 2021).

24. Greer, L. L., de Jong, B. A., Schouten, M. E., Dannals, J. E. Why and When Hierarchy Impacts Team Effectiveness: A Meta-Analytic Integration. Journal of Applied Psychology 2018, 103(6), 591-613. https://doi.org/10.1037/apl0000291

25. Cyranoski, D., Gilbert, N. Ledford, H., Nayar, A., Yahia, M. Education: The PhD factory, Nature 2011, 472, 276-279, https://doi.org/10.1038/472276a.

26. Castelló, M., Pardo, M., Sala-Bubaré, A., Suñe-Soler, N. Why do students consider dropping out of doctoral degrees? Institutional and personal factors. Higher Education 2017, 74, 1053-1068. https://doi.org/10.1007/s10734-016-0106-9.

27. Arbor Award 2015 recipient: Carol Nash. Available http://history.med.utoronto.ca/content/new-book-tells-remarkable-story-medicine-u-t (accessed on 17 January 2021).

28. King, P. In their own words: Meet this year's OISE Leaders \& Legends Awards winners; May 27, 2020. Available online: https://www.oise.utoronto.ca/oise/News/2020/Meet this year_s OISE Leaders and Legends Awards winners.html (accessed on 17 January 2021).

29. Nash, C. Reconsidering Privilege: How to Structure Writing Prompts to Develop Narrative. Survive E Thrive: A Journal for Medical Humanities and Narrative as Medicine 2020, 5(2)3. Available online:

https://repository.stcloudstate.edu/survive thrive/vol5/iss2/3 (accessed on 22 January 2010)

30. Nash C. Challenges Identifying and Stimulating Self-Directed Learning in Publicly Funded Programs, The Digital Era of Education: Novel Teaching Strategies and Learning Approaches Designed for Modern Students. Hauppauge, NY: Nova Science Publishers, Inc., 2020; pp 259-300.

31. Nash, C. Overcoming the Reluctance of Medical Professionals to Embrace Self-Directed Learning in Response to COVID-19. Proceedings 2021. https://doi.org/10.3390/ECERPH-3-08986.

32. Nash, C. Report on Digital Literacy in Academic Meetings during the 2020 COVID-19 Lockdown. Challenges 2020, 11, 20. https://doi.org/10.3390/challe11020020.

33. Fischer, E. How to Practise Philosophy as Therapy: Philosophical Therapy and Therapeutic Philosophy. Metaphilosophy 2011, 42, 49-82. https://doi.org/10.1111/j.1467-9973.2010.01680.x

34. Deka, J. A Russellian Plea for 'Useless' Knowledge: Role of Freedom in Education. Studies in Philosophy and Education 2021, 40 (1), 23-37. https://doi.org/10.1007/s11217-020-09736-7.

35. Nash, C. Doodling as a Measure of Burnout in Healthcare Researchers. Culture, Medicine and Psychiatry 2020. https://doi.org/10.1007/s11013-020-09690-6.

36. Greenhalgh, T., Thorne, S., \& Malterud, K. Time to challenge the spurious hierarchy of systematic over narrative reviews? European journal of clinical investigation 2018, 48(6), e12931. https://doi.org/10.1111/eci.12931.

37. Pilot, A., Bulte, A.M.W. Why Do You "Need to Know"? Context-based education. International Journal of Science Education 2006, 28(9), 953-956, https://10.1080/09500690600702462.

38. Miller T. Doing Narrative Research? Thinking Through the Narrative Process. In: Woodiwiss J., Smith K., Lockwood K. (eds). Feminist Narrative Research. Palgrave Macmillan, London, 2017; pp 39-63. https://doi.org/10.1057/978-1-137-48568-7_3

39. Pears, D. Wittgenstein's concept of showing. Grazer Philosophische Studien 1992, 42, 91.

40. Majka W. Truth and the Phenomenological Landscape of Perception, Respectus Philologicus 2012, 22(27), 11-20. https://doi.org/10.15388/Respectus.2012.27.15333.

41. Weissensteiner E., Winter S. Landmarks in the Communication of Route Directions. In Geographic Information Science; Egenhofer M.J., Freksa C., Miller H.J. (eds) GIScience Lecture Notes in Computer Science, 3234. Springer, Berlin, Heidelberg, 2004; pp 313-326. https://doi.org/10.1007/978-3-540-30231-5_21. 
42. Wittgenstein, L. (1958). Philosophical Investigations, Second Edition; Translated by G.E.M. Anscombe; Oxford: Basil Blackwell, 1958.

43. Nogueiras, G., Iborra, A. Understanding and Promoting Self-Direction in Freshman and Master's Students: A Qualitative Approach. Behavioral Development Bulletin 2017, 22(2), 394-404.

44. Wang, T., Li, L. Tell me what to do 'vs. 'guide me through it': Feedback experiences of international doctoral students. Active $\begin{array}{lllll}\text { Learning in } & \text { Higher } & \text { Education } & \text { 12(2), }\end{array}$ https://doi.org/10.15388/Respectus.2012.27.15333doi.org/10.1177/1469787411402438.

45. Gardner, S.K. "What's too much and what's too little?": The Process of Becoming an Independent Researcher in Doctoral Education, The Journal of Higher Education 2008, 79(3), 326-350, https://doi.org/10.1080/00221546.2008.11772101.

46. Pyne J, Grodsky E. Inequality and Opportunity in a Perfect Storm of Graduate Student Debt, Sociology of Education 2020, 93(1), 20-39. https://doi.org/10.1177/0038040719876245

47. Ray, Subhajyoti. Selecting a Doctoral Dissertation Supervisor: Analytical Hierarchy Approach to the Multiple Criteria Problem. International Journal of Doctoral Studies 2007, 2, 23-32, https://doi.org/10.28945/55

48. Hall, D. T., Yip, J., Doiron, K. Protean Careers at Work: Self-Direction and Values Orientation in Psychological Success, Annual Review of Organizational Psychology and Organizational Behavior 2018, 5(1), 129-156. https://doi.org/10.1146/annurev-orgpsych-032117-104631.

49. Moen T. Reflections on the Narrative Research Approach. International Journal of Qualitative Methods 2006. 56-69. https://doi.org/10.1177/160940690600500405.

50. Vorobyova, M., \& Kochukhova, E. On the Way to Non-Hierarchical Communication: Methods of Reading and Writing in Teaching Philosophy to University Students. KnE Social Sciences 2020, 4(2), 136-148. https://doi.org/10.18502/kss.v4i2.6322.

51. Roberts, D.H., Newman, L.R., Schwartzstein, R.M. Twelve tips for facilitating Millennials 'learning. Medical Teacher 2012, 34(4), 274-278. https://doi.org/10.3109/0142159X.2011.613498

52. Epperly, D. Evidence For COVID-19 Vaccine Deferred Dose 2 Boost Timing. January 5, 2021. Available at SSRN: https://ssrn.com/abstract=3760833 (accessed on 23 January 2021).

53. Schmidt, C. New COVID Vaccines Need Absurd Amounts of Material and Labor. Scientific American January 4, 2021. Available at: https:/www.scientificamerican.com/article/new-covid-vaccines-need-absurd-amounts-of-material-and-labor1/ (accessed on 23 January 2021).

54. Kharroubi S and Saleh F. Are Lockdown Measures Effective Against COVID-19? Frontiers in Public Health $2020,8: 549692$. https://doi.org/10.3389/fpubh.2020.549692

55. Sahu P. Closure of Universities Due to Coronavirus Disease 2019 (COVID-19): Impact on Education and Mental Health of Students and Academic Staff. Cureus 2020, 12(4), e7541. https://doi.org/10.7759/cureus.7541

56. Killgore, W.D.S., Taylor, E.C., Cloonan, S.A., Dailey, N.S. Psychological resilience during the COVID-19 lockdown. Psychiatry Research 2020, 291. https://doi.org/10.1016/j.psychres.2020.113216.

57. Min, J-A., Yu, J.J., Lee, C-U., Chae, J-H. Cognitive emotion regulation strategies contributing to resilience in patients with depression and/or anxiety disorders. Comprehensive Psychiatry 2013, 54(8), $1190-1197$. https://doi.org/10.1016/j.comppsych.2013.05.008.

58. Paetow, G., Zaver, F., Gottlieb, M., Chan, T. M., Lin, M., \& Gisondi, M. A. (2018). Online Mastermind Groups: A Non-hierarchical Mentorship Model for Professional Development. Cureus 2018, 10(7), e3013. https://doi.org/10.7759/cureus.3013.

59. Lee, M.Y., Edmondson, A.C. Self-managing organizations: Exploring the limits of less-hierarchical organizing, Research in Organizational Behavior 2017, 37, 35-58. https://doi.org/10.1016/j.riob.2017.10.002. 
60. DePauw K.P. (2019) Evolving Landscape of Global Higher Education: Challenges and Opportunities from a Graduate Education Perspective. In: Badran A., Baydoun E., Hillman J. (eds) Major Challenges Facing Higher Education in the Arab World: Quality Assurance and Relevance Springer, Cham. 2019. https://doi.org/10.1007/978-3-030-03774-1_6. 